\title{
Basicity Characterization of Imidazolyl Ionic Liquids and Their Application for Biomass Dissolution
}

\author{
Chao Liu $\mathbb{D}^{1,2}$ Youming Li, ${ }^{1,2}$ and Yi Hou $\mathbb{D}^{1,2}$ \\ ${ }^{1}$ State Key Laboratory of Pulp and Paper Engineering, South China University of Technology, Guangzhou 510640, China \\ ${ }^{2}$ National Engineering Research Center of Papermaking and Pollution Control, South China University of Technology, \\ Guangzhou 510640, China
}

Correspondence should be addressed to Yi Hou; ceyhou@scut.edu.cn

Received 11 September 2017; Revised 7 November 2017; Accepted 6 December 2017; Published 30 January 2018

Academic Editor: Bhaskar Kulkarni

Copyright (C) 2018 Chao Liu et al. This is an open access article distributed under the Creative Commons Attribution License, which permits unrestricted use, distribution, and reproduction in any medium, provided the original work is properly cited.

\begin{abstract}
Alkalinity determination is of crucial significance for the applications of basic ionic liquids with imidazolyl. In this work, the ionization constant $\mathrm{p} K_{b}$ value and acid function $\mathrm{H}_{-}$values of ionic liquids synthesized were calculated by $\mathrm{pH}$ method and UV spectrum-Hammett method. The dissolution ratio of biomass in these ionic liquids was measured at different temperatures. Finally, the relationship between the alkalinity and structure of these ionic liquids was discussed, and the relationship between the alkalinity of ionic liquid and the dissolution mechanism biomass was also discussed. The results show that the basicity of carboxylate ionic liquids is determined mainly by their anions, whereas cations take some finely tuned roles. Furthermore, cations and anions are equally important and are involved in dissolution mechanisms.
\end{abstract}

\section{Introduction}

Since the discovery of air- and water-stable ionic liquids (ILs) by Wilkes in 1992 [1], the research and development $(\mathrm{R} \& \mathrm{D})$ of ILs have attracted the keen interest of both scientists and engineers [2-4]. Ionic liquids (ILs), generally defined as organic salts that melt below $100^{\circ} \mathrm{C}$, have been closely studied because they are designable, thermally stable, nonvolatile, and capable of dissolving even polymeric compounds [5-7]. Such properties have led to an explosion in their applications as green, designable solvents for a variety of processes linked to green chemistry and clean technology [8-10]. The introduction of the specific functional group in ionic liquid anions or cations is to form functional ILs [11,12]. Functionalized ILs can be divided into chiral ionic liquids, acidic ionic liquids, basic ionic liquids, reagents, and catalysts supported by ionic liquids and so on [13-15].

Among them, the basic ionic liquid is a kind of important functional ionic liquid in recent development $[16,17]$. Basic ionic liquids not only have the physical properties and advantages of conventional ILs but also have the advantages of inorganic bases, such as stable performance in water and air, being easy to separate, reuse, and adjust, being noncorrosive, being nonvolatile, and can be mixed with many organic solvents. It can not only be used as a solvent in the reaction medium but also can be used as a catalyst. At present, it has played an important role in various fields such as catalysis, adsorption, and separation [18-20]. Recently, cellulose reprecipitated after being dissolved in ILs could show enhanced enzymatic hydrolysis because of a decrease in its crystallinity [21]. Given that ILs can dissolve not only cellulose but also biomass [22], many researchers have extended this IL-assisted method of cellulose pretreatment to various lignocellulosic biomasses [23-25]. Some of them have demonstrated an IL-assisted fractionation of carbohydrate and lignin from lignocellulosic biomass for enhancing enzymatic hydrolysis of carbohydrate and/or utilizing lignin as feedstock for valueadded products. However, the acid-base properties of ILs, which are decided by the anions and cations, are also closely related to the dissolution of biomass. Started from the study of basic ionic liquids, the alkalinity characterization methods of basic ionic liquids were studied to lay the foundation for the biomass treatment in this work. 
The characterization of acid and basic strength is an important aspect of the study of acid and alkali substances, which has theoretical and guiding for the development of these substances [26, 27]. However, there are few reports on the study of the alkalinity characterization of basic ionic liquids. It is an urgent need to develop and perfect the alkaline characterization method of basic ionic liquids and deepen the study on the relationship between the basic strength of ionic liquids and their structures. The difference of anions and cations in ionic liquids is also the key to the dissolution ratio. In this work, a series of basic ionic liquid were synthesized and characterized. The ionization constant $\mathrm{p} K_{b}$ value and acid function $\mathrm{H}_{-}$values of a series of basic ionic liquids were determined by $\mathrm{pH}$ method and UV spectrum-Hammett method. The relationship between the basicity and structure of these ionic liquids was discussed. Finally, the dissolution ratio of biomass in these ILs was determined at different temperatures, and the effects of anionic and cationic structure on biomass dissolution ratio were examined.

\section{Experimental}

2.1. Materials. Trimethyl phosphate, N-methylimidazole, $\mathrm{KOH}$, ethyl acetate, potassium acetate, and methanol are all analytically pure. 1-Ethyl-3-methylimidazolium chloride, 1-butyl-3-methylimidazolium chloride, and 1-pentyl-3methylimidazolium chloride were made in the laboratory. ${ }^{1} \mathrm{H}$ NMR $\left(400 \mathrm{MHz}\right.$ ) spectra were measured in DMSO- $\mathrm{d}_{6}$ at room temperature. Chemical shifts $(\delta)$ were reported in ppm, with tetramethylsilane (TMS) as an internal standard. The $\mathrm{pH}$ was measured using a Sartorius PB-10 pH meter (Guangzhou, China). The $\mathrm{H}_{-}$value was measured using a DR6000 UV spectrophotometer (HACH, Germany). Bromothymol blue (BTB) was analytical grade. Eucalyptus robusta Smith as wood materials were collected from Guangdong Paper Company, Guangzhou, China. The biomass was washed, air-dried, and then finely grounded with a grinder and sieved before use.

2.2. Synthesis and Characterization of ILs. In this study, a series of basic ionic liquids were synthesized by the method as shown in Figure 1. The carboxylic acid ionic liquids were obtained by the anion exchange reaction between acetic acid potassium salt and a series of cationic halogen compounds. Hydroxide alkaline ionic liquid was obtained by the anion exchange reaction between hydroxide potassium and a series of cationic halogen compounds.

The synthesis methods of ionic liquids were referenced as listed in $[28,29]$. Ionic liquids are in the following order.

(1) $[\mathrm{Mmim}][\mathrm{DMP}] ;(2)[\mathrm{Emim}][\mathrm{Ac}] ;(3)[\mathrm{Bmim}][\mathrm{Ac}] ;$ (4) [C5mim][Ac]; (5) [Bmim] [OH].

1,3-Dimethyl-imidazole Dimethyl Phosphate ([Mmim][DMP]). ${ }^{1} \mathrm{HNMR}\left(400 \mathrm{M}, \mathrm{d}_{6}\right.$-DMSO): $\delta=3.29(\mathrm{~d}, 2 \mathrm{H}), 3.88(\mathrm{~m}, 3 \mathrm{H})$, $4.77(\mathrm{~s}, 3 \mathrm{H}), 7.90(\mathrm{~m}, 2 \mathrm{H}), 9.70(\mathrm{~s}, 1 \mathrm{H})$.

1-Ethyl-3-methylimidazolium Acetate ([Emim] [Ac]). ${ }^{1} \mathrm{H}$ NMR (400 M, d $\mathrm{d}_{6}$-DMSO): $\delta=1.42(\mathrm{t}, J=7.2 \mathrm{~Hz}, 3 \mathrm{H}), 1.62(\mathrm{~s}, 3 \mathrm{H})$, $3.91(\mathrm{~s}, 3 \mathrm{H}), 4.25(\mathrm{~m}, 2 \mathrm{H}), 7.96(\mathrm{~s}, 1 \mathrm{H}), 7.86(\mathrm{~s}, 1 \mathrm{H}), 10.12(\mathrm{~s}$, $1 \mathrm{H})$.

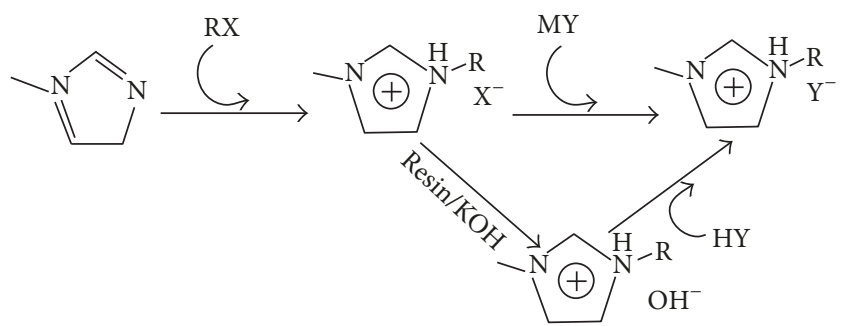

FIGURE 1: Typical preparation routes for ionic liquids $(\mathrm{R}=$ alkyl; $\mathrm{X}=$ $\left.[\mathrm{DMP}]^{-}, \mathrm{Cl}^{-}, \mathrm{Br}^{-}, \mathrm{I}^{-} ; \mathrm{M}=\mathrm{Na}^{+}, \mathrm{K}^{+} ; \mathrm{Y}=[\mathrm{AC}]^{-}\right)$.

1-Butyl-3-methylimidazolium Acetate ([Bmim][Ac]). ${ }^{1} \mathrm{H} \mathrm{NMR}$ (400 M, d $\mathrm{d}_{6}$-DMSO): $\delta=0.87(\mathrm{t}, J=7.2 \mathrm{~Hz}, 3 \mathrm{H}), 1.22(\mathrm{~m}, 2 \mathrm{H})$, $1.53(\mathrm{~s}, 3 \mathrm{H}), 1.74(\mathrm{~m}, 2 \mathrm{H}), 3.84(\mathrm{~s}, 3 \mathrm{H}), 4.16(\mathrm{t}, J=7.2 \mathrm{~Hz}, 2 \mathrm{H})$, $7.74(\mathrm{~d}, J=1.6 \mathrm{~Hz}, 1 \mathrm{H}), 7.81(\mathrm{~d}, J=1.6 \mathrm{~Hz}, 1 \mathrm{H}), 9.71(\mathrm{~s}, 1 \mathrm{H})$.

1-Pentyl-3-methyl Imidazolium ([C5mim][Ac]). ${ }^{1} \mathrm{H}$ NMR $\left(400 \mathrm{M}, \mathrm{d}_{6}-\mathrm{DMSO}\right): \delta=5.56(\mathrm{t}, J=7.2 \mathrm{~Hz}, 3 \mathrm{H}), 5.96(\mathrm{~m}, 2 \mathrm{H})$, $6.37(\mathrm{~s}, 3 \mathrm{H}), 6.51(\mathrm{~m}, 2 \mathrm{H}), 7.88(\mathrm{~s}, 3 \mathrm{H}), 8.64(\mathrm{~s}, J=7.2 \mathrm{~Hz}, 3 \mathrm{H})$, $8.99(\mathrm{~m}, 2 \mathrm{H}), 9.34(\mathrm{~d}, 1 \mathrm{H}), 12.58(\mathrm{~s}, 1 \mathrm{H}), 14.61(\mathrm{~s}, 1 \mathrm{H})$.

1-Butyl-3-methylimidazolium Hydroxide ([Bmim][OH]). ${ }^{1} \mathrm{H}$ NMR (400 M, d $\mathrm{d}_{6}$-DMSO): $\delta=0.81(3, J=7.2 \mathrm{~Hz}, 3 \mathrm{H}), 1.22$ $(\mathrm{m}, 2 \mathrm{H}), 1.71(\mathrm{~m}, 2 \mathrm{H}), 3.80(\mathrm{~s}, 3 \mathrm{H}), 4.20(\mathrm{t}, J=7.2 \mathrm{~Hz}, 2 \mathrm{H})$, $7.78(\mathrm{~d}, J=1.6 \mathrm{~Hz}, 1 \mathrm{H}), 7.86(\mathrm{~d}, J=1.6 \mathrm{~Hz}, 1 \mathrm{H}), 8.49(\mathrm{~s}, 1 \mathrm{H})$.

\subsection{Alkalinity Characterization}

2.3.1. $p H$ Value Method. Basic ionic liquids (1-4): before the experiment, the ionic liquid was dried in a vacuum for $12 \mathrm{~h}$ and then mixed with a certain proportion of water to get the ionic liquid concentration of $0.1,0.01,0.001$, and $0.0001 \mathrm{~mol} \cdot \mathrm{L}^{-1}$. The $\mathrm{pH}$ value was measured by $\mathrm{pH}$ meter, and $\left[\mathrm{H}^{+}\right]$and $\left[\mathrm{OH}^{-}\right]$were calculated. The $K_{b}$ values can be obtained from formula (2). Then the $\mathrm{p} K_{b}$ values were obtained.

2.3.2. UV Spectrum-Hammett Method. Basic ionic liquids (1-5): the same concentration of bromothymol blue indicator was added to the aqueous solution of $0.1 \mathrm{~mol} \cdot \mathrm{L}^{-1} \mathrm{HCl}$ and $\mathrm{NaOH}$, respectively, to determine the UV-Vis absorption in the acid and alkali solution. The alkaline ionic liquid aqueous solution was mixed with $0.1,0.05$, and $0.01 \mathrm{~mol} \cdot \mathrm{L}^{-1}$. The same concentration of bromothymol blue indicator was added to the aqueous solution and the aqueous solution of the basic ionic liquid as reference to for the UV spectrum (time scanning), respectively. By comparing the UV-Vis absorbance in the alkaline aqueous solution, $\mathrm{H}_{-}$was calculated according to function (6).

\subsection{Application of Basic Ionic Liquids in the Field of Biomass Dissolution}

2.4.1. Dissolution of Eucalyptus. $0.2 \mathrm{~g}$ of the Eucalyptus powder was taken for each experiment and $5 \mathrm{~g}$ ionic liquid was added to each sample. A microwave extraction apparatus (XH-100B, XIANGHU Microwave, Beijing, China) was 
chosen to improve the efficiency of wood dissolution in ionic liquids. The pretreatment conditions were as follows: microwave power, $500 \mathrm{~W}$; reaction time, $30 \mathrm{~min}$; and ratio of solid to liquid, $1: 25$. In this paper, all ionic liquid could be recycled 6 to 8 times according to preliminary studies. The dissolution ratio of biomass at the given temperature could be calculated from (1). The dissolution ratio value of biomass in each IL was measured at the temperature range from $80^{\circ} \mathrm{C}$ to $120^{\circ} \mathrm{C}$ with $10^{\circ} \mathrm{C}$ intervals.

Dissolution ratio (\%)

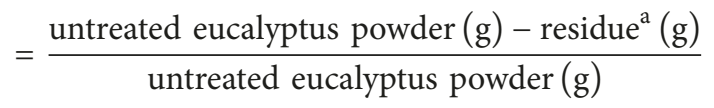

$$
\begin{aligned}
& \times \% \text {, }
\end{aligned}
$$

where ${ }^{a}$ residue is the residual wood powder after the reaction.

2.4.2. Spectroscopic Analysis (FT-IR). FT-IR spectra were recorded on a Nicolet 6700 spectrometer (Vector 33, Bruker, Karlsruhe, Germany) operating in the wavelength range of $4000-400 \mathrm{~cm}^{-1}$. Each sample was coated by potassium bromide $(\mathrm{KBr})$ and formed into a pellet for analysis.

\section{Results and Discussion}

3.1. The Principle of $p H$ Value Method. In the aqueous solution of alkaline ionic liquids, basic anion hydrolysis equilibrium will happen, for example,

$$
\mathrm{B}^{-}+\mathrm{H}_{2} \mathrm{O}=\mathrm{HB}+\mathrm{OH}^{-}
$$

Definition of $K_{b}$ is

$$
K_{b}=\frac{[\mathrm{HB}]\left[\mathrm{OH}^{-}\right]}{\mathrm{B}^{-}}
$$

Mass conservation is

$$
C_{\mathrm{B}^{-}}=\left[\mathrm{B}^{-}\right]+[\mathrm{HB}]=\mathrm{A}^{+}
$$

Charge conservation is

$$
\left[\mathrm{A}^{+}\right]+\left[\mathrm{H}^{+}\right]=\left[\mathrm{B}^{-}\right]+\left[\mathrm{OH}^{-}\right]
$$

Get

$$
C_{\mathrm{B}^{-}} \times \frac{K_{b}}{\left[\mathrm{OH}^{-}\right]+K_{b}}+\left[\mathrm{H}^{+}\right]=\left[\mathrm{OH}^{-}\right]
$$

(The $C_{\mathrm{B}^{-}}$approximation is equal to the concentration of the solution.)

Above all kinds of $[\mathrm{HB}],\left[\mathrm{OH}^{-}\right],\left[\mathrm{B}^{-}\right],\left[\mathrm{A}^{+}\right],\left[\mathrm{H}^{+}\right]$, and $\left[\mathrm{OH}^{-}\right]$are the molar concentration of chemical groups. The $\mathrm{pH}$ value was measured by $\mathrm{pH}$ meter; $\left[\mathrm{H}^{+}\right]$and $\left[\mathrm{OH}^{-}\right]$were calculated. The $K_{b}$ values can be obtained from (6). Then the $\mathrm{p} K_{b}$ values were obtained.
3.2. $p K_{b}$ Value of Alkaline Ionic Liquid. Figure 2 is the $\mathrm{p} K_{b}$ value of basic ionic liquid which is calculated by the $\mathrm{pH}$. As shown in Figure 2, the basicity of ionic liquids with different anions is different. The $\mathrm{p} K_{b}$ of these ILs increase in the order: $[\mathrm{Mmim}][\mathrm{DMP}]<[\mathrm{C} 5 \mathrm{mim}][\mathrm{AC}]<[\mathrm{Bmim}][\mathrm{Ac}]$ $<$ [Emim][Ac]. The $\mathrm{p} K_{b}$ mean values are 10.60, 9.58, 9.48, and 9.25. Therefore, the basicity of these ILs decreased in the order: $[$ Emim $][\mathrm{Ac}]>[\mathrm{Bmim}][\mathrm{Ac}]>[\mathrm{C} 5 \mathrm{mim}][\mathrm{AC}]>$ $[\mathrm{Mmim}][\mathrm{DMP}]$. This is consistent with the principle of acid and alkali; that is, the stronger the acidity, the weaker the basicity of the conjugate base. From the comparison between $[\mathrm{DMP}]^{-}$and $[\mathrm{AC}]^{-},[\mathrm{DMP}]^{-}$is more difficult to dissociate in aqueous solution, and, at the same concentration, the concentration of $[\mathrm{DMP}]^{-}$in aqueous solution is lower. According to (2), the concentration of free $\mathrm{OH}^{-}$decreases, and the alkalinity decreases. The results were similar to those in early reported literatures and showed that the determination results of basic ionic liquids with $\mathrm{p}_{b}$ were reliable and can be applied in the basicity forecast of ionic liquids.

\subsection{The Principle of Hammett Method. UV spectroscopy} (Hammett method) was used to evaluate the concentration of the deprotonated acid indicator (named $\mathrm{B}^{-}$) in aqueous solution. By measuring the ratio of indicator $\left[\mathrm{B}^{-}\right] /[\mathrm{HB}]$, calculate Hammett $\mathrm{H}_{-}$function value:

$$
\begin{aligned}
\mathrm{H}_{-} & =-\lg \frac{\alpha_{H^{+}} \cdot \gamma_{B^{-}}}{\gamma_{\mathrm{HB}}}=\mathrm{p} K(\mathrm{HB})+\lg \frac{\left[\mathrm{B}^{-}\right]}{[\mathrm{HB}]} \\
& =\mathrm{p} K(\mathrm{HB})+\lg \frac{A_{0}-A_{a, \max }}{A_{b, \text { max }}-A_{0}},
\end{aligned}
$$

in which, $\mathrm{p} K(\mathrm{HB})$ is the dissociation constant of acid indicator, and $\left[\mathrm{B}^{-}\right]$and $[\mathrm{HB}]$ are the activity of alkaline species and acidic species, respectively. $\mathrm{H}_{-}$represents an acidic function of a negatively charged conjugate base and its conjugate acid, which indicates the ability to lose protons. The absorbance $A$ in UV absorbance is proportional to the activity of the species, and the basic indicator species and acidic species of absorption peaks vary greatly. Therefore, the absorbance of $\left[\mathrm{B}^{-}\right]$and $[\mathrm{HB}]$ can be substituted for the acidity function of alkaline species and acid species.

3.4. $H_{-}$Value of Basic Ionic Liquid. Figure 3 summarizes the changes of UV-Vis absorption of the bromothymol blue (BTB). It can be seen from Figure 3(a) that there is a strong absorption peak at $440 \mathrm{~nm}$ when the BTB does not react with the base. With the increase of hydroxyl ions, BTB absorption peak at $440 \mathrm{~nm}$ disappeared and redshift in a new absorption peak at $640 \mathrm{~nm}$ and its growing strength. This peak is caused by the transfer of hydrogen from the phenolic group on the molecule. With the increasing of hydroxyl ion concentration, the intensity of absorption peak increases at $640 \mathrm{~nm}$. It is unchanged when it increased to a certain extent. BTB and a large number of hydroxyl ions' interaction make hydrogen on recognition sites away, which increases the electron cloud density of the oxygen atoms on phenolic hydroxyl groups. The conjugation bond on the benzene ring result from the transfer of intramolecular charged, which leads to the new 


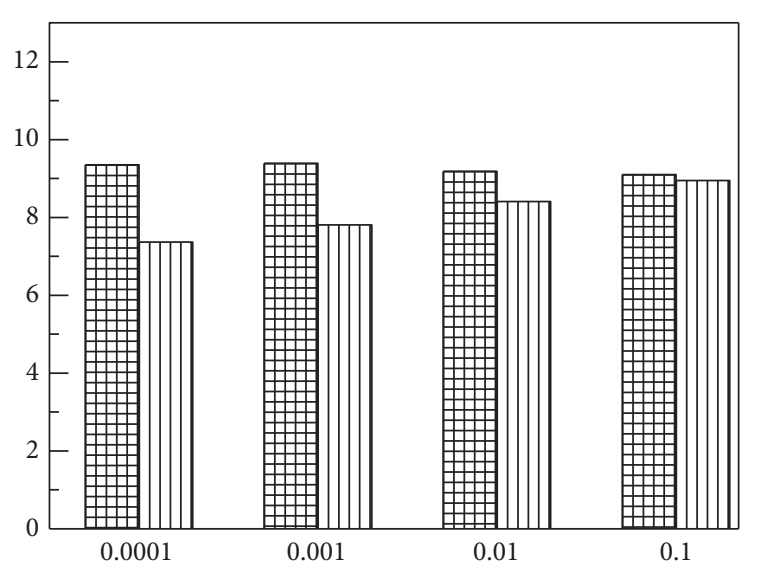

एण丁口
$\mathrm{pH}$
$\mathrm{p} K_{b}$

(a) $[$ Emim $]\left[\right.$ Acc concentration $/\left(\mathrm{mol} \cdot \mathrm{L}^{-1}\right)$

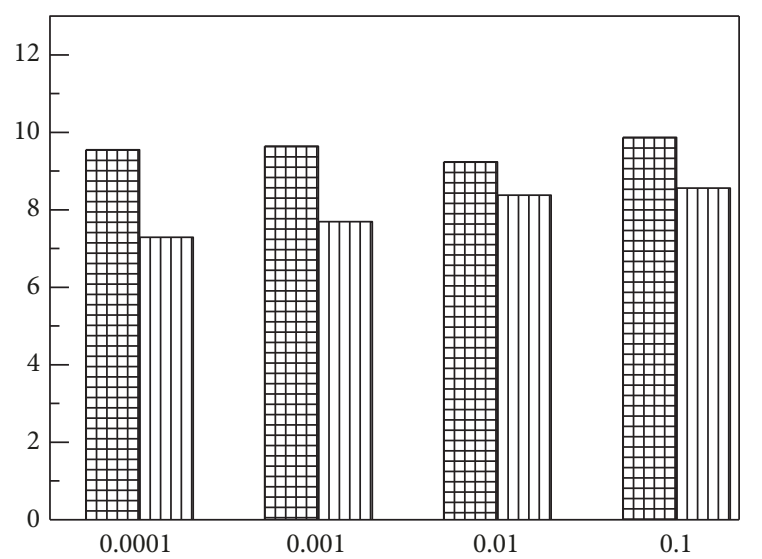

سणा $\mathrm{pH}$ 田四 $\mathrm{p} K_{b}$

(c) $\mathrm{C} 5 \mathrm{mim}][\mathrm{AC}]$ concentration $/\left(\mathrm{mol} \cdot \mathrm{L}^{-1}\right)$

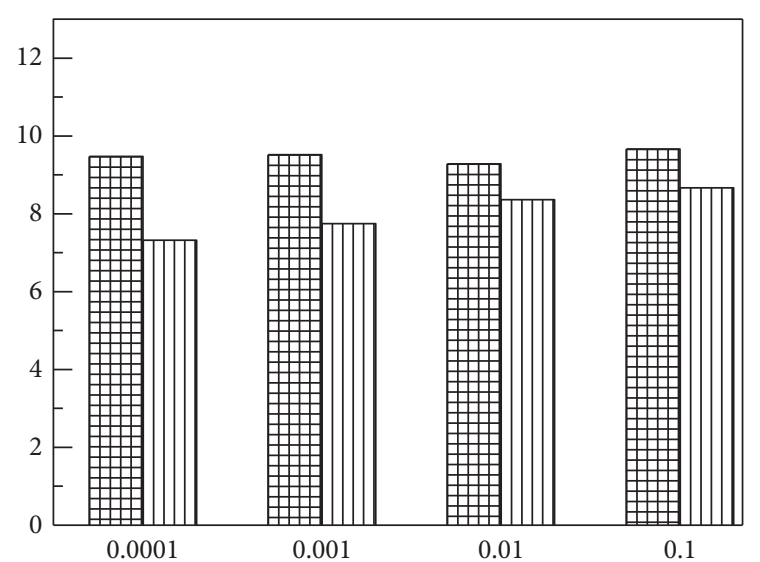

血 $\mathrm{pH}$

册 $\mathrm{p} K_{b}$

(b) Bmim] $[\mathrm{Ac}]$ concentration $/\left(\mathrm{mol} \cdot \mathrm{L}^{-1}\right)$

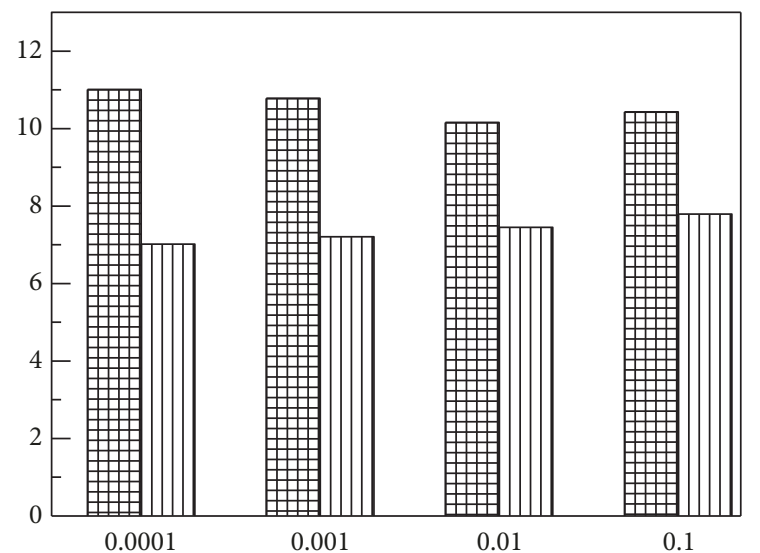

سण $\mathrm{pH}$

回回 $\mathrm{p} K_{b}$

(d) $\mathrm{Mmim}][\mathrm{DMP}]$ concentration $/\left(\mathrm{mol} \cdot \mathrm{L}^{-1}\right)$

FIGURE 2: The $\mathrm{pH}$ and $\mathrm{p} K_{b}$ value of alkaline ionic liquid.

absorption peak appearing at $640 \mathrm{~nm}$. At the same time, the color of the solution of BTB also changed from light yellow to blue. With the increasing of solution concentration of $\mathrm{OH}^{-}$, blue gradually deepened. There are no longer changes when the concentration reaches a certain level; the variation of the curve in Figure 3(a) is consistent with this description.

It can be seen from Figures 3(b), 3(c), and 3(d) that BTB and a large number of acetate ions' interaction make hydrogen on recognition sites away, which result from the transfer of intramolecular charge. These lead to the new absorption peak appearing at $640 \mathrm{~nm}$. The absorption peak of BTB at $640 \mathrm{~nm}$ increases with the increasing of ionic liquid concentration. At the same concentration, the absorption peak of BTB at $640 \mathrm{~nm}$ decreases with the increasing of the alkyl chain. This is because an increase in the length of alkyl chain leads to the electron donating ability weakening, which increases the positive charge density of the imidazole ring. The interaction between BTB and acetate ions was increased and the number of free acetate ions was decreased. Therefore, the stronger the alkaline of ionic liquids, the stronger the absorption peak intensity at $640 \mathrm{~nm}$.

The concentration of BTB was $1.6 \times 10^{-3} \mathrm{~mol} \cdot \mathrm{L}^{-1}$. Dissociation constant of $\mathrm{BTB}$ in aqueous solution: $\mathrm{p} K(\mathrm{HB})=7.3$ [30]. The maximum absorption peak at $640 \mathrm{~nm}$ of the basic $A_{b, \max }=1.60$; acid absorption peak $A_{a, \max }=0$.

It can be seen from Table 1 that the absorption peak of BTB increases with the increasing of ionic liquid concentration. At the same concentration, the absorption peak of BTB decreases with the increasing of the alkyl chain. This is because an increase in the length of alkyl chain leads to the electron donating ability weakening, which increase the positive charge density of the imidazole ring. The interaction between BTB and acetate ions was increased and the number of free acetate ions was decreased. The effect of $\mathrm{H}$ on phenolic hydroxyl groups in BTB molecules is less, and the basicity weakened. And the $[\mathrm{Bmim}][\mathrm{OH}]$ contains strong $\mathrm{OH}^{-}$that 


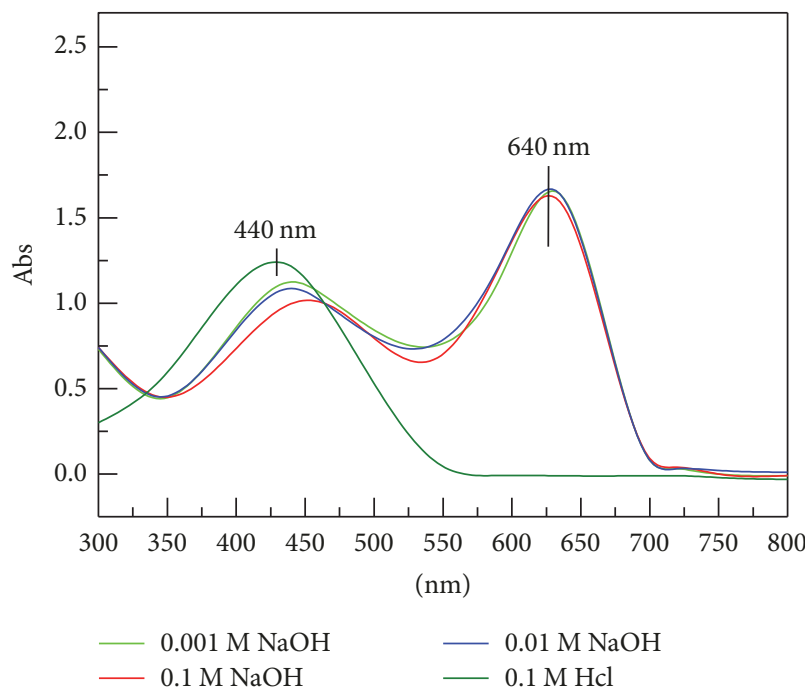

(a)

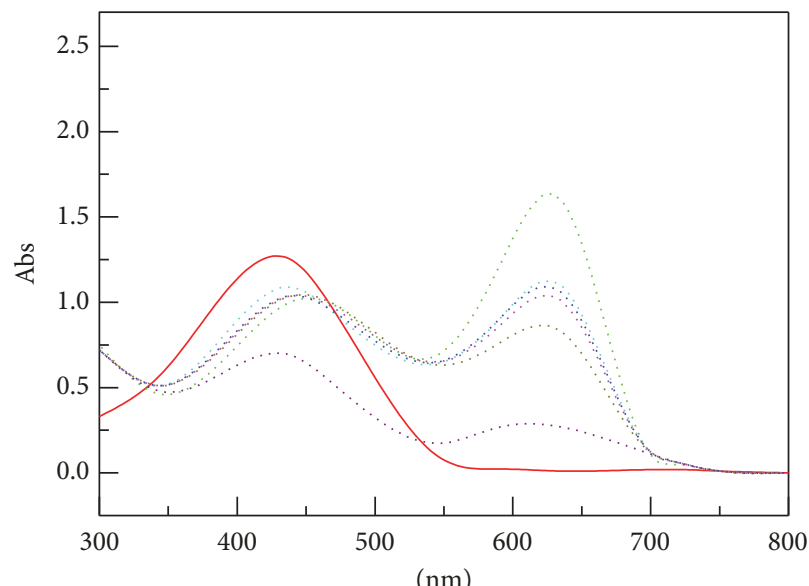

$\begin{array}{llll} & 0.1 \mathrm{M} \mathrm{Hcl}+\mathrm{BTB} & \cdots & 0.05 \mathrm{M}[\mathrm{Bmim}][\mathrm{AC}]+ \\ \cdots \cdots & 0.1 \mathrm{M} \mathrm{NaOH}+\mathrm{BTB} & \mathrm{BTB} \\ \cdots \cdots & 0.05 \mathrm{M}[\mathrm{Bmim}][\mathrm{OH}]+\cdots \cdots & 0.05 \mathrm{M}[\mathrm{C} 5 \mathrm{mim}][\mathrm{AC}]+ \\ & \text { BTB } & \text { BTB } \\ \cdots \cdots & 0.05 \mathrm{M}[\mathrm{Emim}][\mathrm{AC}]+\cdots \cdots & 0.05 \mathrm{M}[\mathrm{Mmim}][\mathrm{DMP}]+ \\ & \text { BTB } & \text { BTB }\end{array}$

(c)

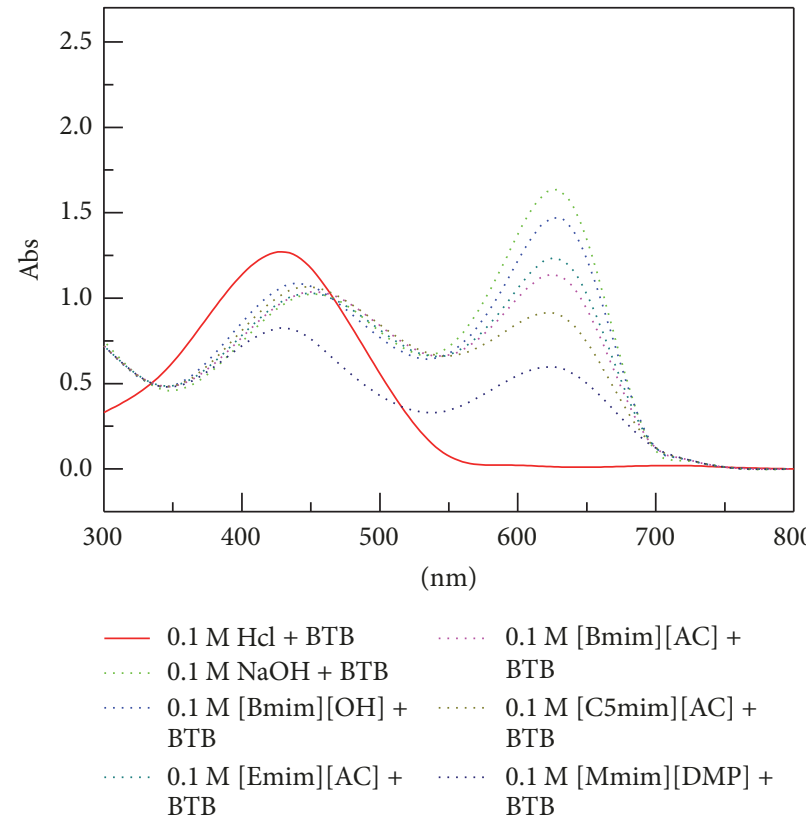

(b)

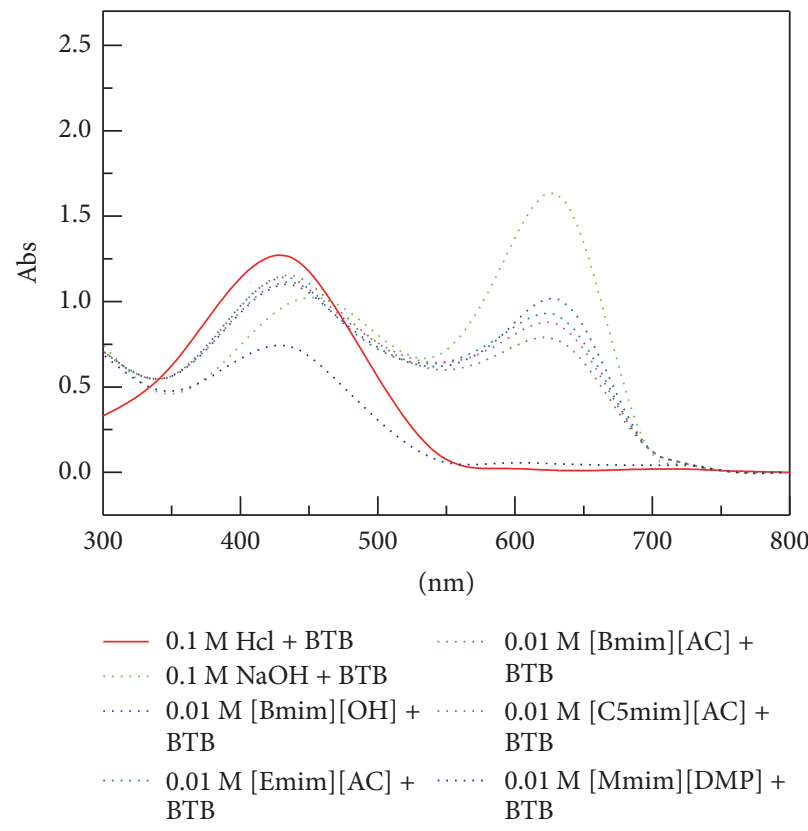

(d)

FIGURE 3: UV-Vis absorption of BTB in alkaline and acidic solutions and in different concentrations of alkaline ionic liquids. ((a) BTB in alkaline and acidic solutions; (b) BTB in $0.1 \mathrm{M}$ ionic liquid; (c) BTB in $0.05 \mathrm{M}$ ionic liquid; (d) BTB in $0.01 \mathrm{M}$ ionic liquid.)

TABLE 1: $H_{-}$values in different concentrations of alkaline ionic liquids.

\begin{tabular}{lccc}
\hline ILs & & H_ in different concentrations $\left(\mathrm{mol} \cdot \mathrm{L}^{-1}\right)$ & \\
& 0.1 & 0.05 & 0.01 \\
\hline$[\mathrm{Mmim}][\mathrm{DMP}]$ & 7.05 & 6.60 & 5.79 \\
{$[\mathrm{C} 5 \mathrm{mim}][\mathrm{Ac}]$} & 7.39 & 7.33 & 7.26 \\
{$[\mathrm{Bmim}][\mathrm{Ac}]$} & 7.66 & 7.53 & 7.30 \\
{$[\mathrm{Emim}][\mathrm{Ac}]$} & 7.79 & 7.59 & 7.41 \\
{$[\mathrm{Bmim}][\mathrm{OH}]$} & 8.29 & 7.64 & 7.52 \\
\hline
\end{tabular}


TABLE 2: Dissolution ratio of biomass in the ILs at different temperatures.

\begin{tabular}{lcccccc}
\hline \multirow{2}{*}{ Entry } & \multicolumn{5}{c}{ Dissolution ratio (\%) } & \multicolumn{7}{c}{ } & & \\
& $\mathrm{IL}$ & $80^{\circ} \mathrm{C}$ & $90^{\circ} \mathrm{C}$ & $100^{\circ} \mathrm{C}$ & $110^{\circ} \mathrm{C}$ & $120^{\circ} \mathrm{C}$ \\
\hline$(1)$ & {$[\mathrm{Mmim}][\mathrm{DMP}]$} & 24.34 & 28.85 & 33.42 & 38.85 & 40.33 \\
$(2)$ & {$[\mathrm{C} 5 \mathrm{mim}][\mathrm{Ac}]$} & 28.62 & 37.03 & 40.62 & 42.35 & 44.83 \\
$(3)$ & {$[\mathrm{Bmim}][\mathrm{Ac}]$} & 31.54 & 38.22 & 44.34 & 48.19 & 50.23 \\
$(4)$ & {$[\mathrm{Emim}][\mathrm{Ac}]$} & 36.36 & 45.24 & 49.33 & 50.24 & 52.12 \\
$(5)$ & {$[\mathrm{Bmim}][\mathrm{OH}]$} & 27.53 & 34.80 & 36.78 & 37.66 & 37.05 \\
\hline
\end{tabular}

TABLE 3: Band assignments for FTIR spectra.

\begin{tabular}{lc}
\hline Band $\left(\mathrm{cm}^{-1}\right)$ & Assignment \\
\hline $3200-3500$ & O-H vibrations \\
1730 & C=O stretching vibration \\
1591 & Aromatic skeletal vibration breathing with $\mathrm{C}=\mathrm{C}$ stretching \\
1503 & Aromatic skeletal vibration \\
1260 & asymmetric bending in $\mathrm{CH}_{3}$ \\
1251 & C-O vibration in the syringyl ring \\
1050 & C-O stretching vibration in cellulose $/$ hemicellulose \\
890 & C-H deformation vibration in cellulose \\
\hline
\end{tabular}

are difficult to ionize in water, which made its basicity stronger. The basicity of these ILs decreased in the order: $[\mathrm{Bmim}][\mathrm{OH}]>[\mathrm{Emim}][\mathrm{Ac}]>[\mathrm{Bmim}][\mathrm{Ac}]>[\mathrm{C} 5 \mathrm{mim}][\mathrm{Ac}]$ $>[\mathrm{Mmim}][\mathrm{DMP}]$.

\subsection{Dissolution of Eucalyptus Powder}

3.5.1. Anionic and Cationic Structure Dependence of Dissolution Ratio. Table 2 summarizes the relationship between the dissolution ratio of Eucalyptus and the basic ionic liquids. It is evident from Table 2 that both cation and anion influence biomass dissolution ratio. From 80 to $90^{\circ} \mathrm{C}$, the dissolution efficiency of Eucalyptus in imidazolium acetate ionic liquids is significantly higher than imidazolium phosphate ionic liquids. Larger anion size results in a reduction of dissolution; hence it contributes to low ability of H-bonds formation. Within limit, with the increasing of alkalinity of the acetate ionic liquid, the dissolution ratio is increasing. It proved that smaller alkyl-side chain on cations boosts up the dissolution ratio. It is interesting that the maximum dissolution ratio of $[\mathrm{Bmim}][\mathrm{OH}]$ treated is lower than that of other ionic liquid. Its dissolution ratio should be greater. It may be the $[\mathrm{Bmim}][\mathrm{OH}]$ is unstable. The introduction of hydroxyl groups and the temperature increasing lead to the breakage of the imidazole ring. All these can lead to the decrease of the dissolution ratio.

3.5.2. FT-IR Analysis of Treated and Untreated Wood Materials. FT-IR analyses of the Eucalyptus residue after its extraction by basic ionic liquids with imidazolyl are presented in Figure 4. The FT-IR spectra for the presence of hydroxyl, carbonyl, and carboxyl functional groups, respectively, were analyzed according to literature in Table 3. All these basic ionic liquids were able to dissolve significant amounts of the refined Eucalyptus, even though they have been previously

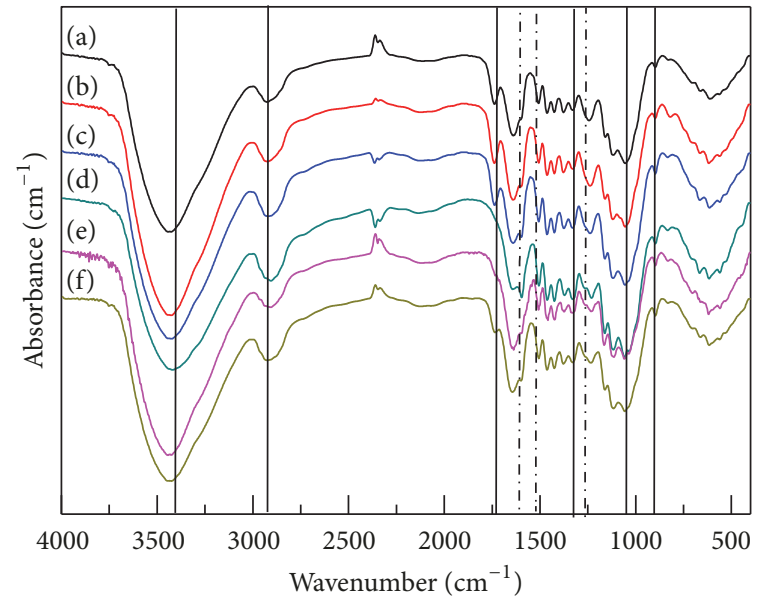

FIgURE 4: FT-IR spectra of the insoluble Eucalyptus fraction after treatment with different basic ionic liquids ((a) untreated; (b) $[\mathrm{Mmim}][\mathrm{DMP}] ; \quad$ (c) $[\mathrm{C} 5 \mathrm{mim}][\mathrm{Ac}] ; \quad$ (d) $[\mathrm{Bmim}][\mathrm{Ac}] ;$ (e) $[$ Emim $][\mathrm{Ac}] ;$ (f) $[\mathrm{Bmim}][\mathrm{OH}])$.

observed to enable significant dissolution of polysaccharides in lignocellulosic composites [23]. However, replacing the phosphate with various carboxylate anions, namely, acetate, caused the dissolution efficiency to increase significantly. The band at $1730 \mathrm{~cm}^{-1}$ in the original Eucalyptus (Figure 4(a)) comes from a $\mathrm{C}=\mathrm{O}$ stretching vibration in acetyl groups of hemicellulose. After BEING treated by [Bmim][Ac] and [Emim][Ac], this band disappears, indicating that some hemicellulose was lost in the washing step. But when treated by other ionic liquids, the peak is still here, just changing the intensity of the peak.

The characteristic peaks of lignin at $1591 / 1503 \mathrm{~cm}^{-1}(\mathrm{C}=\mathrm{C}$ stretching vibration), $1260 \mathrm{~cm}^{-1}$ (asymmetric bending in 


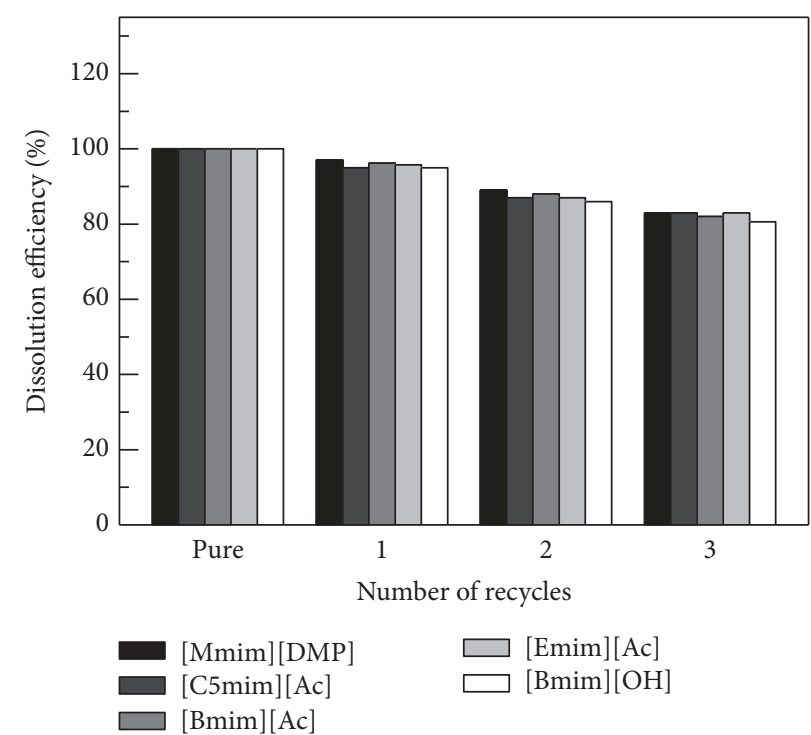

FIGURE 5: The dissolution efficiency of biomass in pure and recycled ILs.

$\mathrm{CH}_{3}$ ), and $1251 \mathrm{~cm}^{-1}$ (C-O vibration in the syringyl ring) remained in the IL-treated sample but with lower intensity when compared with those from the untreated sample. This decrease in intensity is due to partial removal of lignin during IL treatment. It is interesting that both anions and cations affect the dissolution, as illustrated by the changes in the intensity of the peak. The absorbance bands at 1050 and $890 \mathrm{~cm}^{-1}$, corresponding to C-O stretching vibration in cellulose/hemicellulose and $\mathrm{C}-\mathrm{H}$ deformation vibration in cellulose, respectively, were more resolved in ILs treated materials, indicating that the ILs treated materials are richer in carbohydrates. These results are consistent with the results obtained from the dissolution rate.

3.5.3. Effect of Solvent Recycling. The recyclability of the solvent without losing its extraction efficiency is essential to achieve economical and environmentally friendly biomass processing. To demonstrate this, the recovered solvent was subjected to rotary vacuum evaporation for $6 \mathrm{~h}$ at $70^{\circ} \mathrm{C}$. The recovered mass of the ILs after recycling was found to be more than 95\% (Figure 5), which indicated these basic ionic liquids as a potentially good recyclable solvent. The reduction in dissolution efficiencies may be due to the water content of the solvent. The recovery efficiency of $[\mathrm{Bmim}][\mathrm{OH}]$ is the lowest due to the water content of the solvent and it is extremely unstable.

\section{Conclusions}

(1) Five basic ionic liquids were synthesized and characterized, and their $\mathrm{p} K_{b}$ value and $\mathrm{H}_{-}$values were determined by $\mathrm{pH}$ method and UV spectrum-Hammett method. The results show that $\mathrm{p} K_{b}$ values and $\mathrm{H}_{-}$values can identify sorting the alkalinity strength of basic ionic liquids effectively.
(2) The relationship between the structure of imidazolyl ionic liquid and its alkalinity was investigated; the alkalinity was related not only to the length of alkyl chain in imidazole ring but also to the dissociation activity of anions; the results also show that the Hammett method can be applicable in a variety of solvents to be expected as a routine method for the alkalinity characterization of ionic liquids.

(3) The smaller size of aromatic heterocyclic cation and smaller alkyl-side chain boost up the biomass dissolution. As a whole, both cation and anion influence biomass dissolution and are equally important and are involved in dissolution mechanism. In addition, the stronger basicity of the ionic liquid does not necessarily mean the higher dissolution ratio.

\section{Conflicts of Interest}

The authors declare that they have no conflicts of interest.

\section{Acknowledgments}

The authors are grateful for the support of the National Key Research and Development Plan (Grant no. 2017YFB0307901), the National Natural Science Foundation of China (Grant no. 21476091), and the Science and Technology Planning Project of Guangdong Province (Grant no. 2015A020215009). The authors also appreciate the financial support from Science and Technology Planning Project of Foshan in Guangdong Province (Grant no. 2015AG10011).

\section{References}

[1] E. E. Zvereva, S. A. Katsyuba, and P. J. Dyson, "A simple physical model for the simultaneous rationalisation of melting points and heat capacities of ionic liquids," Physical Chemistry Chemical Physics, vol. 12, no. 41, pp. 13780-13787, 2010.

[2] S. Zhang, K. Dokko, and M. Watanabe, "Porous ionic liquids: Synthesis and application," Chemical Science, vol. 6, no. 7, pp. 3684-3691, 2015.

[3] T. Torimoto, T. Tsuda, K.-I. Okazaki, and S. Kuwabata, "New frontiers in materials science opened by ionic liquids," Advanced Materials, vol. 22, no. 11, pp. 1196-1221, 2010.

[4] A. Rehman and X. Zeng, "Ionic liquids as green solvents and electrolytes for robust chemical sensor development," Accounts of Chemical Research, vol. 45, no. 10, pp. 1667-1677, 2012.

[5] K. Ninomiya, K. Inoue, Y. Aomori et al., "Characterization of fractionated biomass component and recovered ionic liquid during repeated process of cholinium ionic liquid-assisted pretreatment and fractionation," Chemical Engineering Journal, vol. 259, pp. 323-329, 2015.

[6] H. Olivier-Bourbigou, L. Magna, and D. Morvan, "ChemInform Abstract: Ionic Liquids and Catalysis: Recent Progress from Knowledge to Applications," ChemInform, vol. 41, no. 23, pp. 156, 2010.

[7] X. Wang, Y. Nie, X. Zhang, S. Zhang, and J. Li, "Recovery of ionic liquids from dilute aqueous solutions by electrodialysis," Desalination, vol. 285, pp. 205-212, 2012.

[8] N. Yaghini, L. Nordstierna, and A. Martinelli, "Effect of water on the transport properties of protic and aprotic imidazolium ionic 
liquids-an analysis of self-diffusivity, conductivity, and proton exchange mechanism," Physical Chemistry Chemical Physics, vol. 16, no. 20, pp. 9266-9275, 2014.

[9] J. Palomar, J. Lemus, N. Alonso-Morales, J. Bedia, M. A. Gilarranz, and J. J. Rodriguez, "Encapsulated ionic liquids (ENILs): From continuous to discrete liquid phase," Chemical Communications, vol. 48, no. 80, pp. 10046-10048, 2012.

[10] A. Guleria, A. K. Singh, and S. Adhikari, "Optical properties of irradiated imidazolium based room temperature ionic liquids: New microscopic insights into the radiation induced mutations," Physical Chemistry Chemical Physics, vol. 17, no. 16, pp. 11053-11061, 2015.

[11] A. George, K. Tran, T. J. Morgan et al., "The effect of ionic liquid cation and anion combinations on the macromolecular structure of lignins," Green Chemistry, vol. 13, no. 12, pp. 33753385, 2011.

[12] L. I. N. Tomé, J. F. B. Pereira, R. D. Rogers, M. G. Freire, J. R. B. Gomes, and J. A. P. Coutinho, “"washing-out” ionic liquids from polyethylene glycol to form aqueous biphasic systems," Physical Chemistry Chemical Physics, vol. 16, no. 6, pp. 2271-2274, 2014.

[13] M. J. Earle and K. R. Seddon, "Ionic liquids. Green solvents for the future," Pure \& Applied Chemistry, vol. 72, pp. 10-25, 2009.

[14] R. Sheldon, "Catalytic reactions in ionic liquids," Chemical Communications, no. 23, pp. 2399-2407, 2001.

[15] M. Messali, M. R. Aouad, A. A.-S. Ali, N. Rezki, T. Ben Hadda, and B. Hammouti, "Synthesis, characterization, and POM analysis of novel bioactive imidazolium-based ionic liquids," Medicinal Chemistry Research, vol. 24, no. 4, pp. 1387-1395, 2015.

[16] B. C. Ranu, S. Banerjee, and R. Jana, "Ionic liquid as catalyst and solvent: the remarkable effect of a basic ionic liquid, [bmIm] OH on Michael addition and alkylation of active methylene compounds," Tetrahedron, vol. 63, no. 3, pp. 776-782, 2007.

[17] T. Liebert and T. Heinze, "Interaction of ionic liquids wlth polysaccharides 5 . Solvents and reaction media for the modification of cellulose," Bioresources, vol. 3, no. 2, pp. 576-601, 2008.

[18] Q. Zhang and J. M. Shreeve, "Energetic ionic liquids as explosives and propellant fuels: a new journey of ionic liquid chemistry," Chemical Reviews, vol. 114, no. 20, pp. 10527-10574, 2014.

[19] M. Gericke, P. Fardim, and T. Heinze, "Ionic liquids - Promising but challenging solvents for homogeneous derivatization of cellulose," Molecules, vol. 17, no. 6, pp. 7458-7502, 2012.

[20] R. Fareghi-Alamdari, M. Nadiri Niri, and H. Hazarkhani, "Synthesis and characterization of a new hydroxyl functionalized diacidic ionic liquid as catalyst for the preparation of diester plasticizers," Journal of Molecular Liquids, vol. 227, pp. 153-160, 2017.

[21] A. P. Dadi, S. Varanasi, and C. A. Schall, "Enhancement of cellulose saccharification kinetics using an ionic liquid pretreatment step," Biotechnology and Bioengineering, vol. 95, no. 5, pp. 904910, 2006.

[22] D. A. Fort, R. C. Remsing, R. P. Swatloski, P. Moyna, G. Moyna, and R. D. Rogers, "Can ionic liquids dissolve wood? Processing and analysis of lignocellulosic materials with 1-nbutyl-3-methylimidazolium chloride," Green Chemistry, vol. 9, no. 1, pp. 63-69, 2007.

[23] I. Kilpeläinen, H. Xie, A. King, M. Granstrom, S. Heikkinen, and D. S. Argyropoulos, "Dissolution of wood in ionic liquids," Journal of Agricultural and Food Chemistry, vol. 55, no. 22, pp. 9142-9148, 2007.
[24] S. Lee, T. Doherty, R. Linhardt, and J. Dordick, "Ionic LiquidMediated Selective Extraction of Lignin From Wood Leading to Enhanced Enzymatic Cellulose Hydrolysis," Biotechnology \& Bioengineering, vol. 102, pp. 1368-1376, 2009.

[25] N. Muhammad, W. N. Omar, Z. Man, M. A. Bustam, S. Rafiq, and Y. Uemura, "Effect of ionic liquid treatment on pyrolysis products from bamboo," Industrial \& Engineering Chemistry Research, vol. 51, no. 5, pp. 2280-2289, 2012.

[26] C. Rey-Castro and L. F. Vega, "Transport properties of the ionic liquid 1-ethyl-3-methylimidazolium chloride from equilibrium molecular dynamics simulation. the effect of temperature," The Journal of Physical Chemistry B, vol.110, no. 29, pp.14426-14435, 2006.

[27] C. Hardacre, L. Aldous, V. Parvulescu et al., "Catalysis in ionic liquids," The Royal Society of Chemistry, pp. 10-1021, 2013.

[28] A. Nazet, S. Sokolov, T. Sonnleitner, T. Makino, M. Kanakubo, and R. Buchner, "Densities, Viscosities, and Conductivities of the Imidazolium Ionic Liquids [Emim][Ac], [Emim][FAP], [Bmim][BETI], [Bmim][FSI], [Hmim][TFSI], and [Omim][TFSI]," Journal of Chemical \& Engineering Data, vol. 60, 150715100514003, 2015.

[29] H. F. Sangian, J. Kristian, S. Rahma et al., "Preparation of reducing sugar hydrolyzed from high-lignin coconut coir dust pretreated by the recycled ionic liquid [mmim][dmp] and combination with alkaline," Bulletin of Chemical Reaction Engineering and Catalysis, vol. 10, no. 1, pp. 8-22, 2015.

[30] D. C. Ashworth and R. Narayanaswamy, "The effect of surfactants on the $\mathrm{pH}$ transition interval of bromothymol blue immobilized on XAD 4," Microchimica Acta, vol. 106, no. 3-6, pp. 287-292, 1992. 


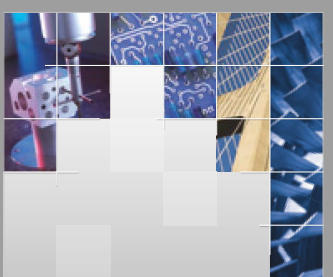

\section{Enfincering}
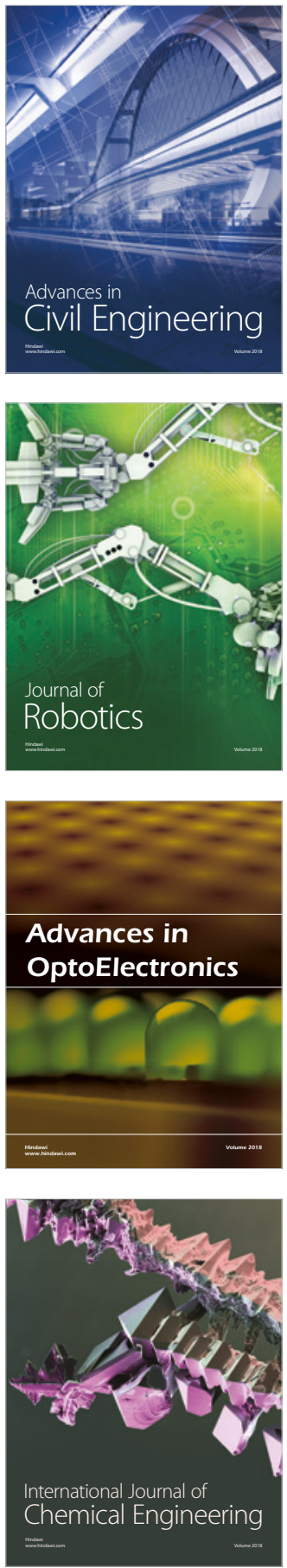

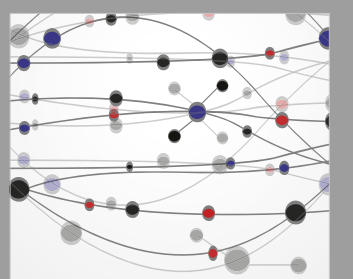

\section{Rotating \\ Machinery}

The Scientific World Journal

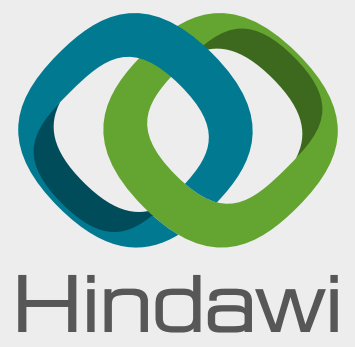

Submit your manuscripts at

www.hindawi.com
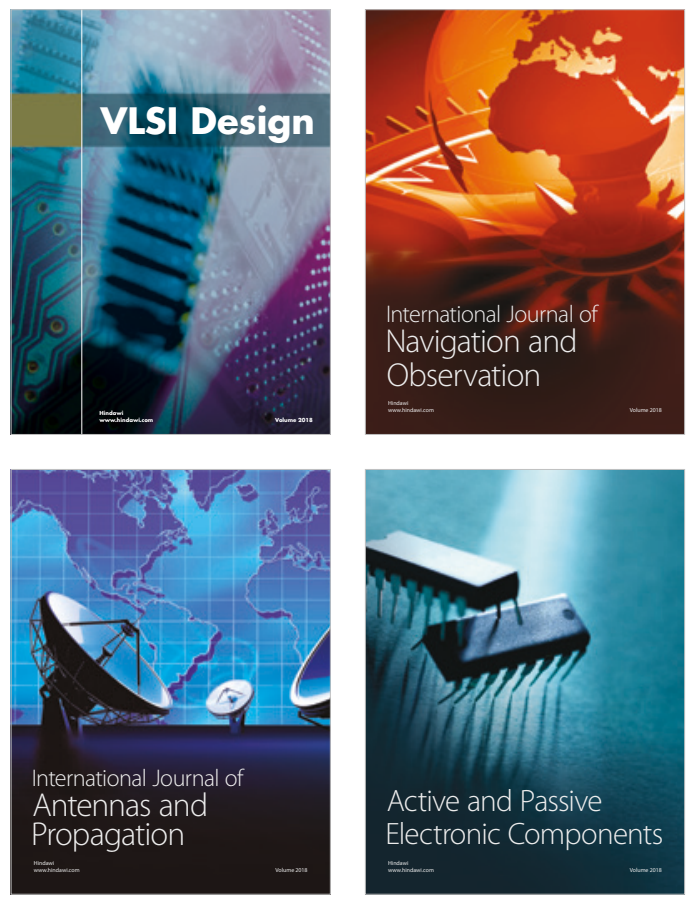
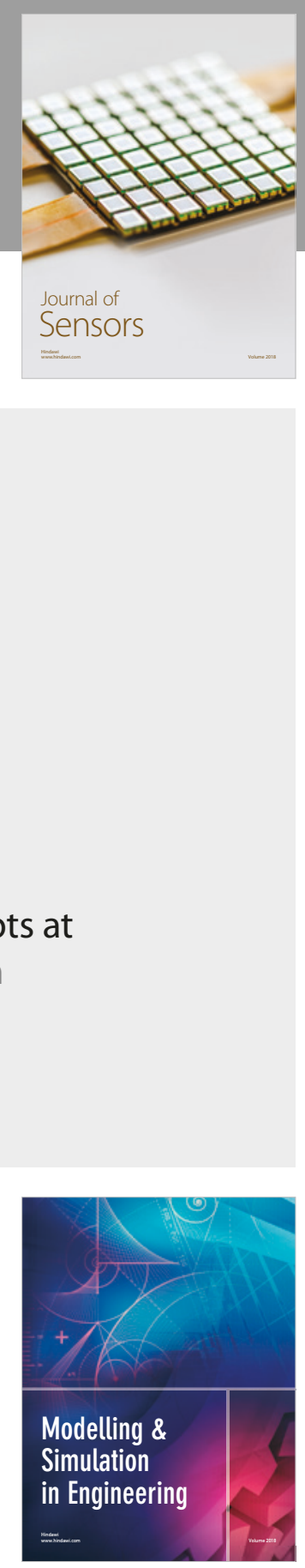

\section{Advances \\ Multimedia}
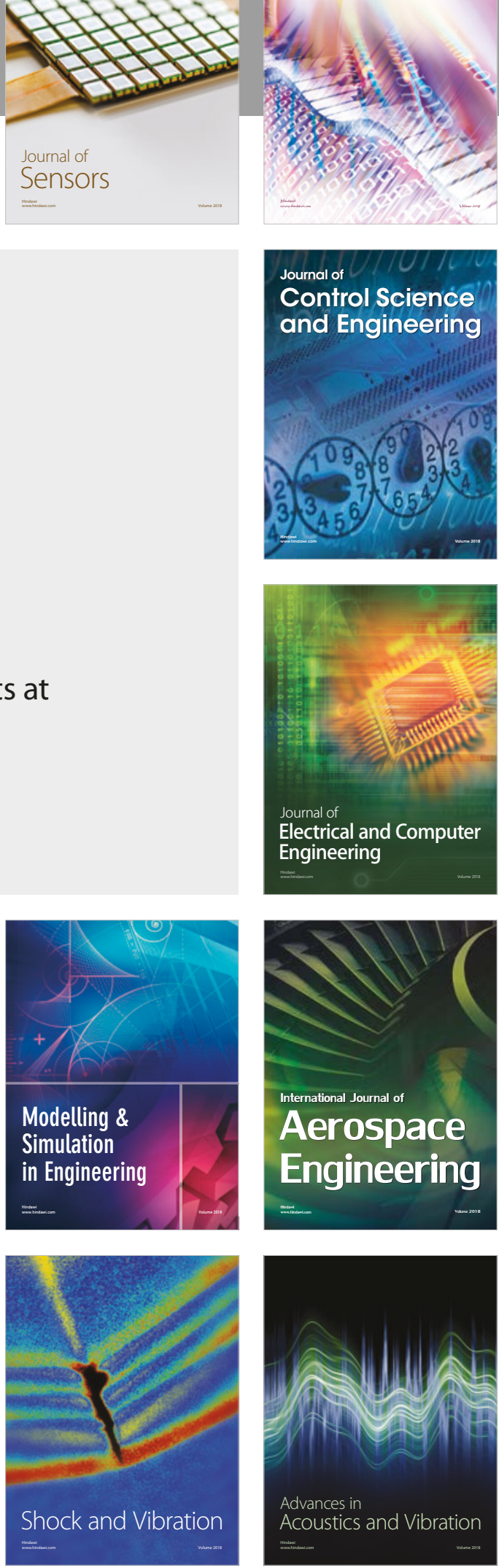